\title{
Antisense Proliferating Cell Nuclear Antigen Oligonucleotides Inhibit Intimal Hyperplasia in a Rat Carotid Artery Injury Model
}

\author{
Michael Simons, * ${ }^{*}$ Elazer R. Edelman, ${ }^{* 11}$ and Robert D. Rosenberg * \\ ${ }^{*}$ Department of Biology and ${ }^{\ddagger}$ Division of Health, Science and Technology, Massachusetts Institute of Technology, Cambridge, \\ Massachusetts 02139; and Departments of Medicine, ${ }^{\S}$ Beth Israel Hospital and "Brigham and Women's Hospital, Harvard Medical \\ School, Boston, Massachusetts 02215
}

\begin{abstract}
We have used antisense phosphorothioate oligonucleotides to define the role played by proliferating cell nuclear antigen (PCNA) in neointimal accumulation of smooth muscle cells in a rat carotid artery injury model. The short-term extraluminal delivery of $250 \mathrm{nmol}$ of antisense oligonucleotides, but not control oligonucleotides, immediately after arterial injury produces a $77 \%$ suppression of PCNA mRNA after $24 \mathrm{~h}$ and a $52 \%$ decrease in the frequency of medial smooth muscle cells expressing PCNA after $72 \mathrm{~h}$. This reduction in PCNA expression is accompanied by a 59\% decrease in the frequency of proliferating medial smooth muscle cells at $3 \mathrm{~d}$ as measured by BudR staining and an $\mathbf{8 0 \%}$ decrease in neointimal accumulation assessed morphometrically at 2 wk. Thus, the expression of PCNA is required for medial smooth muscle cell growth in vivo and for neointimal formation after arterial injury. (J. Clin. Invest. 1994. 93:2351-2356.) Key words: smooth muscle cells • proliferation • animal models • restenosis • polymer gels
\end{abstract}

\section{Introduction}

The proliferation of smooth muscle cells in vitro is stimulated by various mitogens such as PDGF, IGF-1, basic fibroblast growth factor, EGF, IL-1, and TGF- $\beta$ (1-3). The binding of growth factors to specific receptors on smooth muscle cells initiates a complicated series of biochemical reactions which involve protein kinase $C$, receptor-linked tyrosine phosphorylation, and cAMP-dependent kinases (4). The detailed molecular events which immediately follow receptor activation are currently under examination in many laboratories.

The various signal transduction mechanisms stimulated by the activation of different growth factor receptors are likely to intersect with a common pathway of intracellular components required for smooth muscle cell proliferation/migration. Indeed, the growth response in a number of cell types, including smooth muscle cells, to serum mitogens in vitro is suppressed by antisense oligonucleotides directed against c-myc, c-myb, proliferating cell nuclear antigen (PCNA), ${ }^{1}$ cyclins, and non-

Address correspondence to Robert D. Rosenberg, Department of Biology, Massachusetts Institute of Technology, Building E25-229, 77 Massachusetts Avenue, Cambridge, MA 02139.

Received for publication 15 September 1993 and in revised form 30 December 1993.

1. Abbreviations used in this paper: PCNA, proliferating cell nuclear antigen; SV40LT-SMC, smooth muscle cell line immortalized with SV40 large $T$ antigen.

J. Clin. Invest.

(c) The American Society for Clinical Investigation, Inc.

$0021-9738 / 94 / 06 / 2351 / 06 \$ 2.00$

Volume 93, June 1994, 2351-2356 muscle myosins (5-11). Thus, antisense oligonucleotides are useful in defining key intracellular regulatory components which may be critical for the proliferation/migration of smooth muscle cells in vitro.

The biologic role of several growth factors has been established in vivo by suppressing the action of these mitogens in the rat carotid artery injury model and ascertaining the consequences of this experimental manipulation. The results obtained have lead to unexpected conclusions. The intravenous administration of polyclonal neutralizing antibody against PDGF in the above model produces a $40 \%$ reduction of neointimal smooth muscle cell accumulation which is mainly due to the suppression of cell migration (12). The intravenous infusion of polyclonal neutralizing antibody against basic fibroblast growth factor in the same model prevents the first wave of smooth muscle cell growth but does not affect the final extent of neointimal smooth muscle cell accumulation (13).

Until recently, it has been difficult to show that intracellular regulatory components necessary for smooth muscle cell proliferation/migration in vitro are also essential for this process in vivo. This issue is of obvious importance because the characteristics of smooth muscle cells are altered in tissue culture and mitogenic factors in the in vivo setting may include components presently unknown. We have used antisense oligonucleotides to specifically inhibit the synthesis of intracellular regulatory macromolecules in the rat carotid artery model and showed that the protooncogene, c- $m y b$, is critically involved in the proliferation/migration of smooth muscle cells in vivo (14). In the present investigation, we use a similar experimental approach to demonstrate that the expression of PCNA is essential for neointimal smooth muscle cell accumulation. The data also indicate that this cell cycle-dependent protein is necessary for the first wave of proliferation of medial smooth muscle cells.

\section{Methods}

Synthetic oligonucleotides. The two antisense phosphorothioate PCNA oligonucleotides (antisense 1 [GATCAGGCGTGCCTCAAA], nucleotides 4-21 of rat PCNA and antisense 2 [CTTCAGGATGGAGCCCTG], nucleotides 22-39 of rat PCNA) as well as the sense and scrambled control phosphorothioate PCNA oligonucleotides (sense 1 [TTTGAGGCACGCCTGATC] and scrambled 2 [CAGACCGCAGGACTGTAT]) were synthesized in the Massachusetts Institute of Technology Biopolymers Laboratory. The oligonucleotides were deprotected on the column, dried down, resuspended in Tris-EDTA ( 10 mm Tris, $\mathrm{pH} 7.4 ; 1 \mathrm{~mm}$ EDTA, pH 8.0), and quantified by spectrophotometry.

Tissue culture growth assay. All experiments were carried out with a vascular smooth muscle cell line (15) immortalized with SV40 large T antigen (SV40LT-SMC) kindly provided by Dr. Christopher Reilly (Merck Sharpe \& Dohme, West Point, PA). Cells were cultured in DME supplemented with $10 \%$ FBS heat inactivated at $65^{\circ} \mathrm{C}$ for $45 \mathrm{~min}$ ( $10 \%$ FBS-DME). Smooth muscle cells were plated at 25,000 cells/ well in a cluster 6 plate (Bellco Biotechnology, Vineland, NJ) and 
allowed to attach in 10\% FBS-DME. The cells were then washed twice with PBS, and the medium was changed to 0.25\% FBS-DME (growth arrest medium). After $96 \mathrm{~h}$, the cells were shifted to 10\% FBS-DME in the presence of various concentrations of antisense or control PCNA oligonucleotides. The cells were then allowed to grow for an additional $72 \mathrm{~h}$, trypsinized, and counted (Coulter Corp., Hialeah, FL). All experiments were carried out in triplicate and repeated twice.

Rat injury model. Sprague-Dawley rats (average weight $360 \mathrm{~g}$ ) were anesthetized with ketamine $(40 \mathrm{mg} / \mathrm{kg})$ and xylazine $(10 \mathrm{mg} / \mathrm{kg})$, and the left carotid arteries of the animals were isolated via a midline cervical incision. A 2F Fogarty catheter (Baxter Diagnostics, Inc.) was introduced through the left external carotid artery of each rat and advanced to the aortic arch; the balloon was inflated to produce moderate resistance to catheter movement and then was withdrawn gradually to the entry point. The entire procedure was repeated three times for each animal. The oligonucleotides were added at a concentration of $1 \mu \mathrm{mol} /$ $\mathrm{ml}$ to $25 \%$ (wt/vol) solutions of Pluronic ${ }^{\star} \mathrm{F}-127$ prepared as outlined by the manufacturer (BASF-Wyandotte Corp., Wyandotte, MI) and maintained at $4^{\circ} \mathrm{C}$. The solutions were applied immediately to the exposed segment of the artery using prechilled pipettes and pipette tips. The solution was allowed to gel, the wounds were closed, and the animals were returned to their cages. In control animals, the injury was carried out as described above, but no gel was applied.

After 2 wk, the animals were killed by an overdose of ketamine and xylazine and then perfused with $150 \mathrm{~cm}^{3}$ of normal saline under a pressure of $120 \mathrm{mmHg}$. The left carotid arteries were removed, fixed in $10 \%$ formalin, and then processed for light microscopy in a standard manner. The cross sections of four separate left carotid arterial segments from each animal were examined (six cross sections, $5 \mu \mathrm{m}$ apart for each arterial segment). Morphometric measurements were carried out by a single observer who used an automated computer-based image analysis system and was blinded to the nature of the specimen as described previously (16).

$R N A$ analysis. The animals were killed $24 \mathrm{~h}$ after injury, perfused with normal saline, and injured and contralateral carotid arteries were rapidly removed and snap-frozen in liquid nitrogen. The tissue was then pulverized in a liquid nitrogen-cooled metal chamber, taken up in $5 \mathrm{M}$ guanidine thiocyanate, and then sonicated in a blender. Total RNA was then extracted using an RNA extraction kit (Stratagene, La Jolla, CA), and $20 \mu \mathrm{g} /$ well of total RNA was loaded on a Hybond-N nylon membrane (Amersham Corp., Arlington Heights, IL) using a slot blot apparatus (Schleicher \& Schuell, Inc., Keene, NH). The RNA was then cross-linked to the membrane with ultraviolet irradiation (Stratalinker; Stratagene) and prehybridized at $65^{\circ} \mathrm{C}$ with QuikHyb solution (Stratagene) supplemented with $100 \mu \mathrm{g} / \mathrm{ml}$ of sonicated salmon sperm DNA for $2 \mathrm{~h}$. Murine PCNA coding sequence (courtesy of Dr. R. Baserga, Temple University, Philadelphia, PA) and human $\beta$ actin cDNA were radiolabeled to a specific activity of $10^{9} \mathrm{cpm} / \mu \mathrm{g}$ using a random priming kit (Boehringer Mannheim Corp., Indianapolis, IN), purified on G-25 spin columns (Boehringer Mannheim Corp.), and added to QuikHyb solution. The hybridization was carried out at $65^{\circ} \mathrm{C}$ for $2 \mathrm{~h}$. The blots were then washed twice in $2 \times \mathrm{SSC} / 0.1 \%$ SDS solution at room temperature, twice in $0.2 \times$ SSC/ $1 \%$ SDS solution at $65^{\circ} \mathrm{C}$, visualized by autoradiography, and quantified by Betascope 603 blot analyzer (Betagen, Waltham, MA).

Immunocytochemical analysis. In an additional group of experiments, immunocytochemical staining for BudR and PCNA was carried out in six animals killed $72 \mathrm{~h}$ and in six animals killed $14 \mathrm{~d}$ after balloon injury. For the purpose of BudR staining, rats were injected intraperitoneally with BudR $(50 \mathrm{mg} / \mathrm{kg}$ ) (Sigma Immunochemicals, St. Louis, MO) $1 \mathrm{~h}$ before killing. The animals were then killed as described above, and the left carotid arteries were fixed in $10 \%$ formalin. The cross sections from two separate arterial segments of each animal (six cross sections for each arterial segment) were incubated with anti-PCNA (Signet Laboratories, Inc., Dedham, MA) or antiBudR (Sigma Immunochemicals) antibodies used in 1:200 and 1:50 dilutions, respectively, as described previously (17). The stained nuclei were counted by an investigator blinded to the nature of the specimen and were averaged for each animal. The percentage of stained nuclei (PCNA or BudR) was determined as a ratio of stained nuclei to the total number of nuclei in the section used for analysis.

In vitro migration assay. The smooth muscle cell migration assay was carried out in a modified Boyden chamber (Costar Corp., Cambridge, MA) with an 8- $\mu \mathrm{m}$ pore size (diameter) polycarbonate filter (Costar Corp.) dividing upper and lower well chambers. Cultured SV40LT-SMC were trypsinized and suspended at a concentration of 120,000 cells $/ \mathrm{ml}$ in DME supplemented with $0.25 \% \mathrm{FBS}$. A volume of $100 \mu \mathrm{l}$ of cell suspension ( $\sim 12,000$ cells) with $25 \mu \mathrm{M}$ antisense or scrambled PCNA oligonucleotides or no oligonucleotides (control) was placed in an upper chamber, and $1.2 \mathrm{ml}$ of DME supplemented with $10 \%$ FBS was placed in the lower chamber. After $6 \mathrm{~h}$ of incubation at $37^{\circ} \mathrm{C}$ in $5 \% \mathrm{CO}_{2}$-supplemented room air atmosphere, the filter was removed from the chamber, and the number of cells attached to the lower surface of the filter was determined by averaging the number of cells present in five high power fields. This assay system is virtually identical to that used by other investigators to document the action of antisense c-myc oligonucleotides on chemotaxis (8). Each assay was carried out in duplicate, and the experiments were repeated twice. The results are given as percentage of control $\pm \mathrm{SD}$.

\section{Results}

We have used antisense oligonucleotides to PCNA to define the role played by this cell cycle-dependent protein in neointimal smooth muscle cell accumulation in a rat carotid artery injury model. The effect of antisense oligonucleotides in suppressing smooth muscle cell proliferation was tested initially in vitro. The antisense 1 PCNA oligonucleotide produced dose-dependent inhibition of the growth of SV40LT-SMC, while sense 1 control oligonucleotide had no significant effect on cell proliferation (Fig. 1). These data are virtually identical to those reported previously by others for primary vascular smooth muscle cells (11). We also examined the effect of antisense PCNA oligonucleotides on smooth muscle cell migration in an in vitro assay (Boyden chamber). The addition of $25 \mu \mathrm{M}$ antisense 1 or sense 1 control oligonucleotides did not influence the number of migrating cells after $6 \mathrm{~h}$ of exposure $(80 \pm 8.7 \%$ of control vs $88 \pm 6.1 \%$ of control, $P=\mathrm{NS}$ ).

Given the inhibition of smooth muscle cell proliferation by antisense PCNA oligonucleotide in vitro, we next ascertained the action of two nonoverlapping antisense PCNA oligonucleotides on neointimal accumulation in a rat carotid artery injury model. To this end, the left common carotid artery of rats was subjected to balloon angioplasty, which initiates a highly reproducible intimal proliferation/migration of smooth muscle cells over the entire length of the effected blood vessel. The antisense oligonucleotides or the sense or scrambled control oligonucleotides were added to pluronic solutions at $1 \mathrm{mmol} / \mathrm{ml}$. After balloon angioplasty, $250 \mu$ l of solution ( $250 \mathrm{nmol}$ of oligonucleotide) was applied to the injured carotid artery in the neck. On contact with the artery, the solution gelled immediately, generating a translucent layer which enveloped the treated region. The wounds were closed after application of the gel, and the rats were returned to their cages. As noted previously, the pluronic gel is no longer visible $1-2 \mathrm{~h}$ after application.

To assess the efficacy of oligonucleotide-induced suppression of PCNA message, we killed at $24 \mathrm{~h}$ two animals treated with antisense 1 PCNA oligonucleotide and two animals treated with sense 1 control oligonucleotide. RNA analysis revealed significantly decreased amounts of PCNA mRNA in the antisense oligonucleotide-treated animals as compared with 


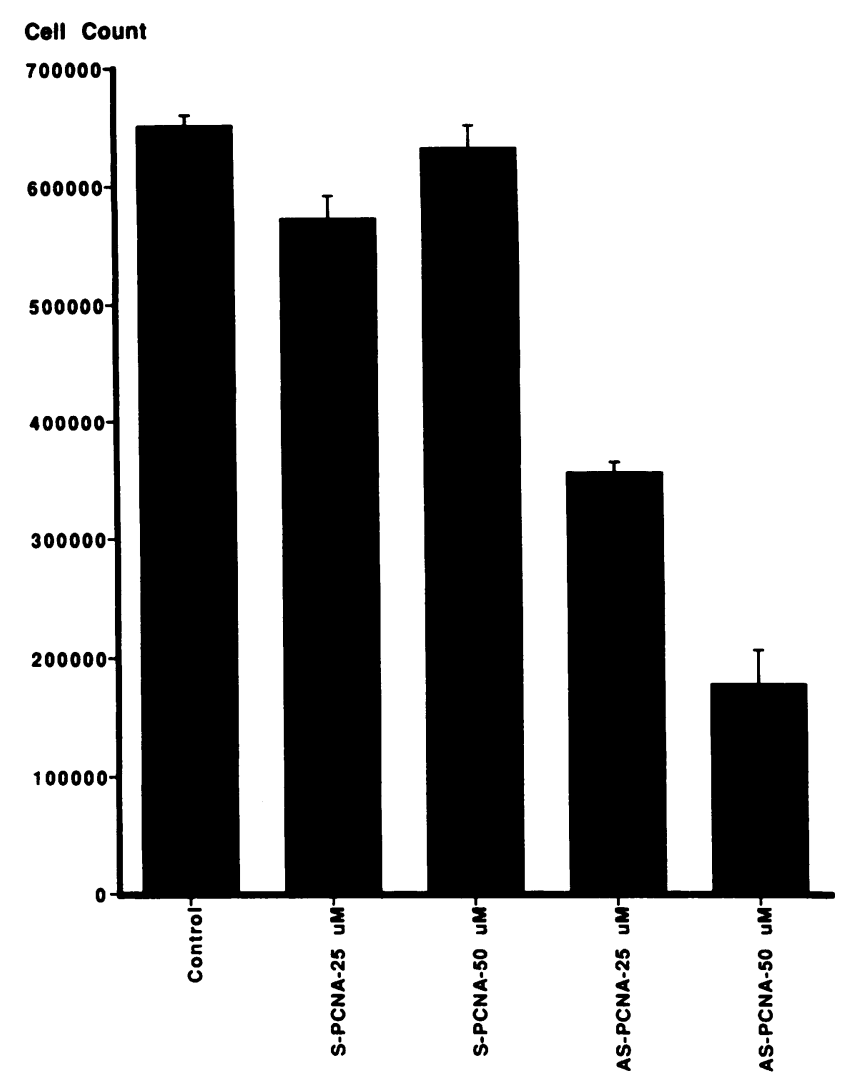

Figure 1. In vitro effect of PCNA oligonucleotides on vascular smooth muscle cell proliferation. Growth-arrested SV40LT-SMC were stimulated with $10 \%$ FBS-DME in the presence of 25 or $50 \mu \mathrm{M}$ antisense 1 phosphorothioate PCNA oligonucleotide ( $A S-P C N A)$ or 25 or $50 \mu \mathrm{M}$ sense 1 phosphorothioate oligonucleotide ( $S-P C N A$ ) or in the absence of oligonucleotide (Control). The bar graph shows cell counts obtained $72 \mathrm{~h}$ later. The data are displayed as mean $\pm \mathrm{SD}$.

the sense oligonucleotide-treated or untreated controls. Hybridization with a $\beta$-actin probe demonstrated relatively equal RNA loading in both groups (Fig. 2). Quantitative analysis of the blots showed an approximate 5.5-fold reduction $(9,221$ $\mathrm{cpm}$ in scrambled control vs $1,683 \mathrm{cpm}$ in antisense-treated animals [lines 1 and 2] and a 3.3 -fold reduction $(6,545 \mathrm{cpm}$ in scrambled controls vs $1,959 \mathrm{cpm}$ in antisense-treated animals [lines 3 and 4]) in PCNA message levels normalized for $\beta$-actin. There was no difference in PCNA RNA levels in sense oligonucleotide-treated and untreated controls $(6,418 \mathrm{cpm}$ in injured untreated arteries vs 6,545 and $9,221 \mathrm{cpm}$ in treated controls).

The initial wave of medial smooth muscle proliferation peaks at $72 \mathrm{~h}$ after balloon angioplasty in the rat carotid artery injury model (18). Given the effective suppression of PCNA message at $24 \mathrm{~h}$, we then investigated the action of antisense 1 PCNA oligonucleotides, as compared with sense 1 control oligonucleotides, on the first wave of medial smooth muscle cell growth. Immunocytochemical analyses showed a 59\% reduction in the frequency of medial smooth muscle cells labeled with a single injection of BudR $1 \mathrm{~h}$ before killing in antisense oligonucleotide-treated animals $(n=3)$ as compared with sense oligonucleotide-treated controls $(n=3)$ (Fig. 3). To ensure representative selection of data, we examined six $5-\mu \mathrm{m}$ sections from two different arterial segments in each animal. The magnitude of medial smooth muscle cell labeling in con-

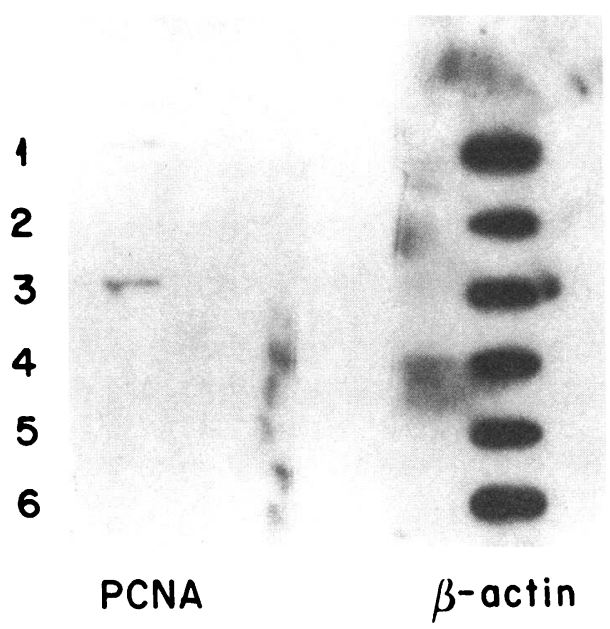

Figure 2. In vivo effect of PCNA oligonucleotides on PCNA RNA expression in rat carotid arteries. $20 \mu \mathrm{g}$ of total RNA from ballooninjured carotid arteries was loaded using a slot blot apparatus on a Hybond-N membrane. Compare PCNA probe hybridization in carotid arteries treated with antisense 1 PCNA oligonucleotide (lines 2 and 4), control sense 1 oligonucleotide (lines 1 and 3 ), and uninjured arteries (lines 5 and 6 ). Hybridization of the same amount of RNA to the $\beta$-actin probe is depicted in the right column.

trol oligonucleotide-treated animals is in accordance with data obtained previously using similar protocols for rat carotid artery balloon injury and BudR staining $(16,17$, and Edelman, E. R., unpublished observations).

We also obtained additional evidence to show that the inhibitory effect of antisense PCNA oligonucleotides is due to suppression of this cell cycle-dependent gene product. In this situation, one might observe a parallel reduction of PCNA expression and BudR staining in medial smooth muscle cells after arterial injury. The above result should not be expected if the antisense oligonucleotide inhibited PCNA expression without a subsequent effect on smooth muscle proliferation and suppressed cell growth by an independent mechanism. Therefore, we determined the frequency of PCNA expression in medial smooth muscle cells $72 \mathrm{~h}$ after arterial injury in six animals. Immunocytochemical analysis revealed a $52 \%$ reduction in the frequency of medial smooth muscle cells expressing PCNA in antisense oligonucleotide-treated animals $(n=3)$ as compared with control oligonucleotide-treated animals ( $n$ $=3$ ) (Fig. 3). There was little difference in the spatial distribution of stained nuclei from different arterial segments of the same animal. These data are virtually identical to the frequency of medial smooth muscle cells staining with BudR at the same point in time (Fig. 3).

Given the above sequence-specific suppression of PCNA $\mathrm{mRNA}$ /protein as well as the reduction in the first wave of smooth muscle cell proliferation, we then assessed the effect of oligonucleotide treatment on neointimal accumulation $2 \mathrm{wk}$ after arterial injury. The administration of antisense PCNA ( $n$ $=14)$, but not control oligonucleotides $(n=8)$, produced a marked decrease in neointimal formation (Fig. 4). No significant difference in inhibitory activity was noted with the two nonoverlapping antisense oligonucleotides (the ratios of intimal to medial cross-sectional areas for antisense 1 and antisense 2 are $0.015 \pm 0.09, n=8$ and $0.014 \pm 0.16, n=6$, respectively), and sense 1 or scrambled 2 control oligonucleotides were also identical with regard to the lack of biologic potency 


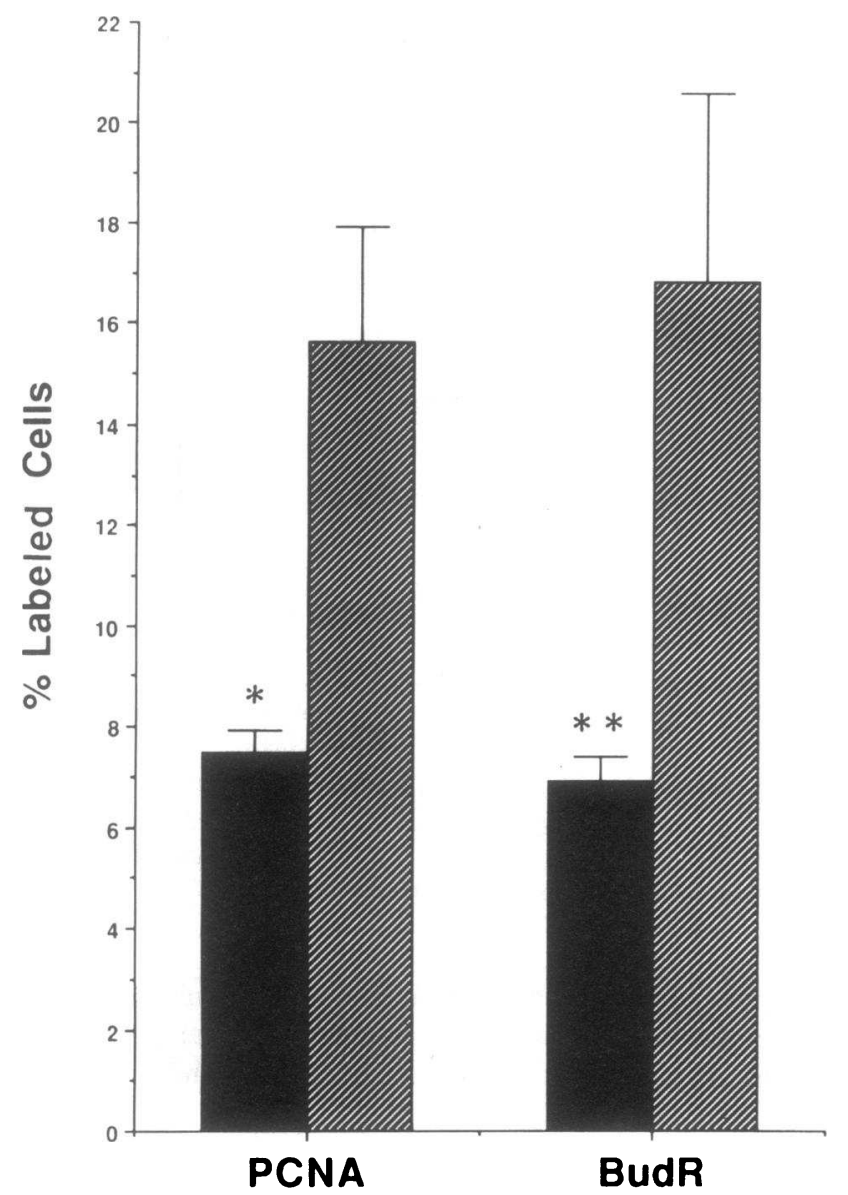

Figure 3. Immunocytochemical analysis of BudR and PCNA expression in medial smooth muscle cells. Rats were subjected to balloon injury and killed at $72 \mathrm{~h}$, left carotid arteries were perfusion fixed, and representative sections were stained for BudR and PCNA as described in Methods. The fraction of labeled cells was determined as a ratio of cells stained with anti-BudR or anti-PCNA antibody to the total number of cells in each section. The bar graph shows percentage of labeled cells in rats treated with antisense 1 oligonucleotide (dark bars) or sense 1 oligonucleotide (stippled bars). The data are displayed as mean \pm SD. ${ }^{*} P=0.01 ;{ }^{* *} P=0.03$. (the ratios of intimal to medial cross-sectional areas for sense 1 control and scrambled 2 control are $0.86 \pm 0.16, n=5$ and $1.01 \pm 0.18, n=3$, respectively). Therefore, the above data were combined into antisense PCNA oligonucleotide-treated and control oligonucleotide-treated groups. The animals treated with antisense PCNA oligonucleotides exhibit an $80 \%$ reduction in neointimal area as compared with those treated with control oligonucleotides or those undergoing balloon injury only (Fig. $5 \mathrm{~A}$ ). The antisense PCNA oligonucleotide, control oligonucleotide, and untreated groups of animals were indistinguishable with regard to medial area. The animals treated with antisense PCNA oligonucleotide exhibit an $84 \%$ reduction in the ratio of intima/media cross-sectional areas as compared with those treated with control oligonucleotides or those subjected to balloon injury only (Fig. $5 B$ ). To determine the likelihood of further intimal proliferation at this point in time, we carried out immunocytochemical staining for PCNA in three antisense oligonucleotide-treated rats and in three control oligonucleotide-treated rats. In both sets of animals, there was only minimal PCNA staining ( $<1 \%$ of the cells), indicating a drop of PCNA levels in controls and a further decline of PCNA expression in antisense-treated rats.

\section{Discussion}

We have demonstrated previously that inhibiting the expression of the protooncogene, c-myb, arrests smooth muscle cell growth in vitro and suppresses neointimal smooth muscle cell accumulation in vivo in the rat carotid artery injury model (14). These data suggest that the above protooncogene is a member of the common pathway of intracellular components used by mitogens to facilitate smooth muscle cell proliferation / migration in vivo. The role played by c-myb in smooth muscle proliferation/migration is not understood completely, but the protooncogene appears to be involved in regulating the $G_{1} / S$ phase transition, possibly by initiating an elevation of calcium ion at this stage of the cell cycle $(19,20)$. In fibroblast cell lines, constitutive overexpression of $c-m y b$ posttranscriptionally elevates the levels of PCNA, suggesting that this cell cycle-dependent protein may be a critical link between c-myb and proliferation/migration of various cell types (21).

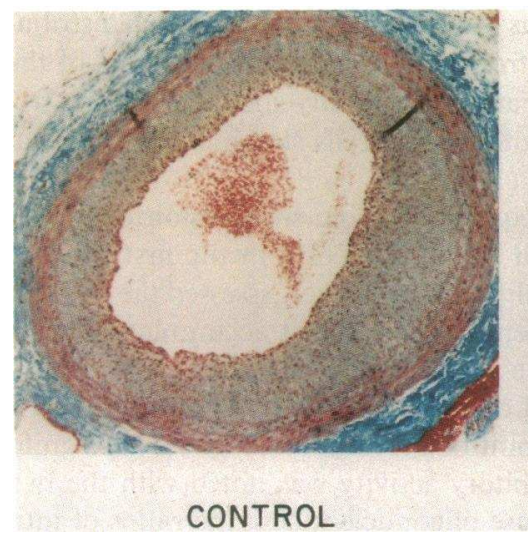

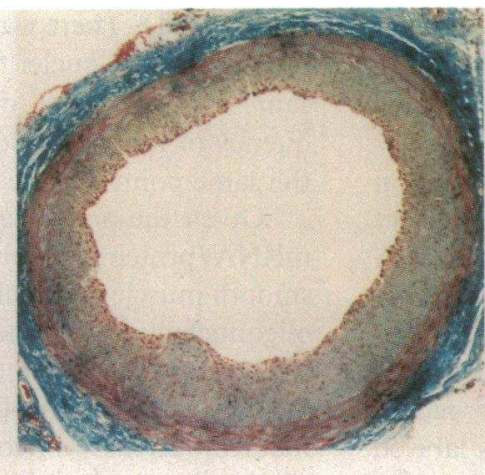

SCR PCNA

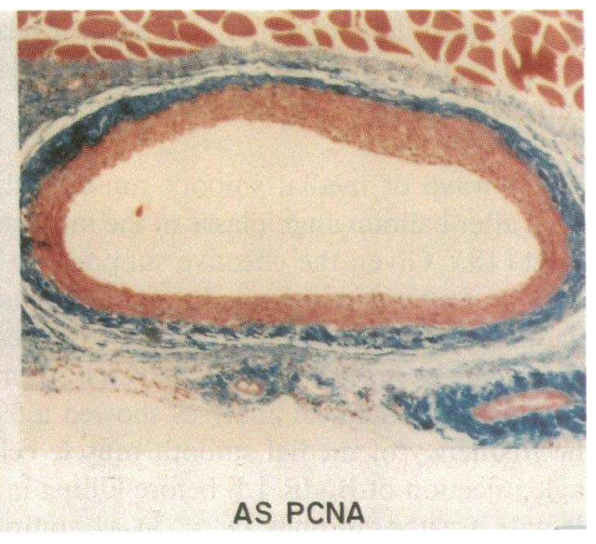

Figure 4. The effect of antisense and control PCNA oligonucleotides on neointimal formation in the rat carotid artery injury model. Representative cross sections from the left carotid artery of a rat treated with pluronic gel containing $250 \mathrm{nmol}$ of antisense 1 phosphorothioate oligonucleotide ( $A S P C N A$, right), a rat treated with pluronic gel containing $250 \mathrm{nmol}$ of sense 1 phosphorothioate oligonucleotide (SCR PCNA, middle), or an untreated rat (CONTROL, left) (Mason trichrome; $\times 80)$. 

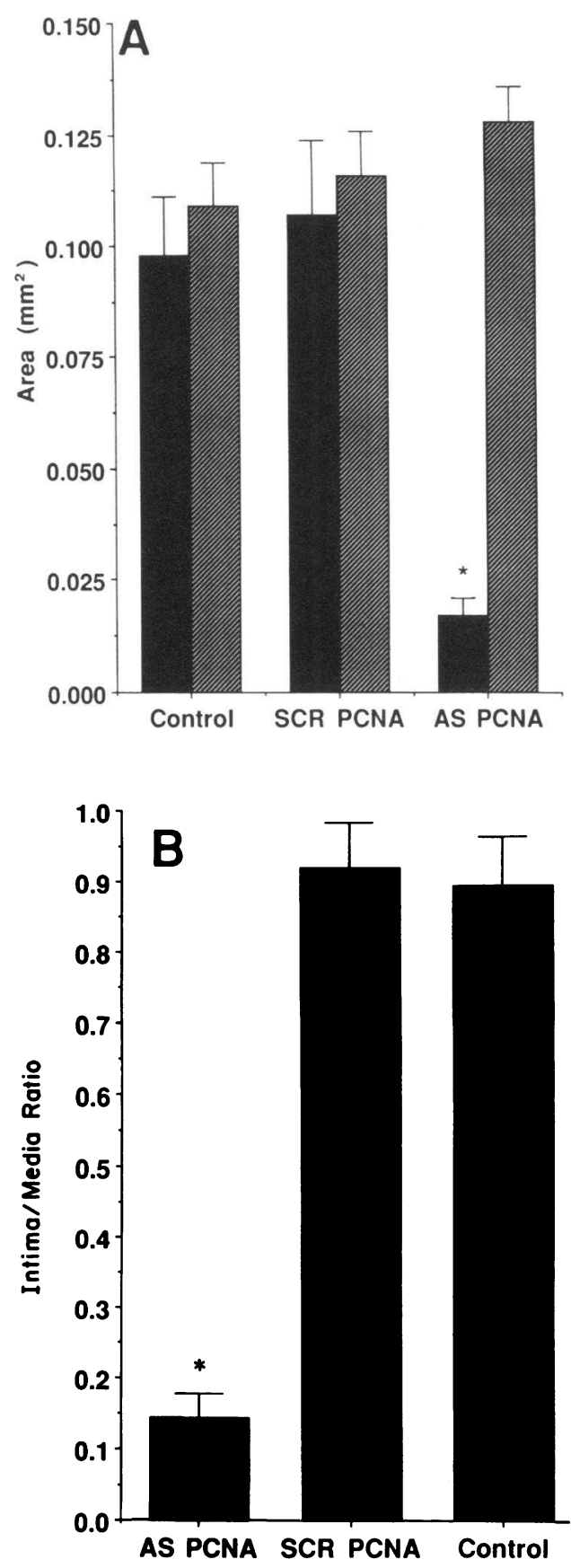

Figure 5. Morphometric analysis of treated and untreated rat carotid arteries. Mean cross-sectional areas (Fig. $5 \mathrm{~A}$ ) of the intimal (black bars) and medial (stippled bars) regions of rat carotid arteries that were treated with a pluronic gel that contained $250 \mathrm{nmol}$ of antisense $1(n=8)$ or antisense $2(n=6)$ oligonucleotide $(A S P C N A)$ or a pluronic gel that contained $250 \mathrm{nmol}$ of sense $1(n=5)$ or scrambled $2(n=3)$ oligonucleotide (SCR PCNA) or were untreated (Control). $B$ depicts the ratios of intima to media in the same groups of animals. The data are displayed as mean \pm SD. ${ }^{*} P<0.01$.

PCNA was described originally as a nuclear antigen but was identified later as an auxiliary subunit of DNA polymerase $\delta$ (22-24). This cell cycle-specific protein is thought to function by coordinating leading and lagging DNA strand synthesis at the replication fork (25). PCNA is required for in vitro growth of several cell lines, including vascular smooth muscle cells, as suggested by the antiproliferative effect of antisense oligonucle- otides $(5,11)$. However, the ability of the PCNA gene product to regulate cell proliferation/migration in vivo has not been established. Therefore, we examined the role of this cell cyclespecific protein with regard to neointimal smooth muscle cell accumulation in the rat carotid artery injury model.

Our investigations show that expression of PCNA in medial smooth muscle cells is required for neointimal smooth muscle cell accumulation after arterial injury. This conclusion is documented by the significant decrease in neointimal smooth muscle cell accumulation after administration of antisense PCNA oligonucleotides, but not control oligonucleotides. At the same time, antisense or control oligonucleotides have no effect on medial smooth muscle cell density, suggesting that inhibition of PCNA expression reduces the proliferation of medial smooth muscle cells but is not responsible for cell death via a nonspecific mechanism. The importance of PCNA with regard to cell proliferation was established by showing that the frequency of proliferating medial smooth muscle cells $72 \mathrm{~h}$ after arterial injury is decreased significantly in antisense PCNAtreated animals but not in control oligonucleotide-treated animals.

We note a small discrepancy in antisense PCNA-treated animals with regard to the $77 \%$ reduction in PCNA message at $24 \mathrm{~h}$ and the $52 \%$ reduction in the number of anti-PCNA antibody-stained cells at $72 \mathrm{~h}$ as compared with the $80 \%$ suppression of neointimal formation at $14 \mathrm{~d}$. These minor discrepancies may be because of the lack of a linear relationship between the frequency of anti-PCNA antibody-staining cells, the amount of PCNA protein in cells, and the ability of cells to proliferate. Alternatively, the small differences between the effect of antisense PCNA oligonucleotides on smooth muscle cell proliferation at $72 \mathrm{~h}$, as measured by staining of cells for BudR and PCNA, and neointimal formation at $14 \mathrm{~d}$ could indicate that smooth muscle cell migration may also be affected by this treatment. To evaluate this possibility, we carried out in vitro motility experiments with Boyden chambers and were unable to document any effect of antisense PCNA oligonucleotides on smooth muscle cell migration. Finally, the discrepancy between these two sets of data may indicate that a moderate inhibition of medial smooth muscle cell proliferation during the first $3 \mathrm{~d}$ after injury is sufficient to produce a more profound subsequent decrease in smooth muscle cell growth and/or matrix production leading to a major decrease in neointimal formation at a later point in time. This observation is supported further by the fact that neointimal and medial cell PCNA levels declined further in both control and antisense oligonucleotidetreated animals, reaching essentially undetectable levels, suggesting that further escape from proliferation arrest in antisense-treated animals is unlikely at this point. This is consistent with the findings of Morishita et al. (26) who showed no change in neointimal formation after antisense cdc2 kinase/ PCNA treatment when observation was extended from 2 to 8 wk.

The use of antisense oligonucleotides to delineate the biologic function of specific macromolecules is sometimes criticized because of potential side effects such as cleavage of homologous mRNAs, nonspecific sequence-dependent effects of oligonucleotides, or the activation of p68 kinase by cDNA/ mRNA hybrids $(27,28)$. To exclude these possibilities, we used two nonoverlapping PCNA antisense oligonucleotides as well as scrambled and sense control oligonucleotides. The virtually identical extent of inhibition of neointimal smooth mus- 
cle cell accumulation by the two nonoverlapping antisense oligonucleotides and the lack of any decrease in this parameter by scrambled or sense control oligonucleotides document the specificity of the result. Furthermore, the antisense PCNA oligonucleotides, but not control oligonucleotides, produced a significant decrease in PCNA mRNA as well as a very similar reduction in the frequency of medial smooth muscle cells which stain for PCNA and BudR at the stage of maximum cell proliferation. These observations make it unlikely that the antisense oligonucleotides inhibit PCNA expression without a subsequent effect on smooth muscle cell proliferation and suppress cell growth by an independent mechanism.

The proliferation of vascular smooth muscle cells is responsible for postangioplasty coronary artery restenosis, the failure of coronary and peripheral arterial bypass grafts, and the diffuse narrowing of coronary arteries after cardiac transplantation $(29,30)$. A similar pathologic process probably underlies development of atherosclerosis and hypertension (31). As noted above, we have learned much about the numerous growth factors and cytokines that trigger smooth muscle cell proliferation, but we know relatively little about intracellular pathways which mediate the abnormal growth response. $\mathrm{Nu}$ merous techniques for suppressing smooth muscle cell growth in vivo have been evaluated, which include methods for inhibiting specific growth factors (for review see reference 32 ). The lack of complete success in this endeavor argues that a different approach may be useful. We have reasoned that elucidating key components in a final common pathway necessary for the action of all mitogens could provide a powerful alternative for controlling vascular smooth muscle cell growth. The investigations outlined above indicate that inhibition of PCNA expression may be useful in this regard and suggest that antisense oligonucleotides could provide a means to achieve this end.

\section{Acknowledgments}

This work was supported in part by National Institutes of Health (NIH) grants HL-33014 and HL-41484, NIH Physician-Scientist Award K12 AG00294, and American Heart Association Clinician Scientist Award 9100420.

\section{References}

1. Schwartz, S. M., G. R. Campbell, and J. H. Campbell. 1986. Replication of smooth muscle cells in vascular disease. Cir. Res. 58:427-444.

2. Banscota, N. K., R. Taub, K. Zellner, and G. L. King. 1989. Insulin, insulin-like growth factor I and platelet derived growth factor interact additively in the induction of the proto oncogene c-myc and cellular proliferation in cultured bovine aortic smooth muscle cells. Mol. Endocrinol. 3:1183-1190.

3. Libby, P., S. J. C. Warner, and G. B. Friedman. 1988. Interleukin 1: a mitogen for human vascular smooth muscle cells that induces the release of growth-inhibitory prostanoids. J. Clin. Invest. 81:487-498.

4. Berridge, M. J. 1993. Inositol triphosphate and calcium signalling. Nature (Lond.). 361:315-325.

5. Jaskulski, D., J. K. DeRiel, W. E. Mercer, B. Calabretta, and R. Baserga. 1988. Inhibition of cellular proliferation by antisense oligodeoxynucleotides to PCNA cyclin. Science (Wash. DC). 240:1544-1546.

6. Degols, G., J. P. Leonetti, N. Mechti, and B. Lebleu. 1991. Antiproliferative effects of antisense oligonucleotides directed to the RNA of c-myc oncogene. Nucleic Acids Res. 19:945-948.

7. Gewirtz, A. M., and B. Calabretta. 1988. A c-myb antisense oligodeoxynucleotide inhibits normal human hematopoiesis in vitro. Science (Wash. DC) 242:1303-1306.
8. Biro, S., Y. M. Fu, Z. X. Yu, and S. E. Epstein. 1993. Inhibitory effects of antisense oligodeoxynucleotides targeting c-myc mRNA on smooth muscle cell proliferation and migration. Proc. Natl. Acad. Sci. USA 90:654-658.

9. Brown, K. E., M. S. Kindy, and G. E. Sonnenshein. 1992. Expression of the c-myb proto-oncogene in bovine vascular smooth muscle cells. J. Biol. Chem. 267:4625-4630.

10. Simons, M., and R. D. Rosenberg. 1992. Antisense nonmuscle myosin heavy chain and c-myb oligonucleotides suppress smooth muscle cell proliferation in vitro. Circ. Res. 70:835-843.

11. Speir, E., and S. E. Epstein. 1992. Inhibition of smooth muscle cell proliferation by an antisense oligodeoxynucleotide targeting the messenger RNA encoding proliferating cell nuclear antigen. Circulation. 86:538-547.

12. Ferns, G. A. A., E. W. Raines, K. H. Sprugel, A. S. Motani, M. Reidy, and R. Ross. 1991. Inhibition of neointimal smooth muscle accumulation after angioplasty by an antibody to PDGF. Science (Wash. DC). 253:1129-1132.

13. Lindner, V., and M. A. Reidy. 1991. Proliferation of smooth muscle cells after vascular injury is inhibited by an antibody against basic fibroblast growth factor. Proc. Natl. Acad. Sci. USA. 88:3739-3743.

14. Simons, M., E. R. Edelman, J.-L. DeKeyser, R. S. Langer, and R. D. Rosenberg. 1992. Antisense c-myb oligonucleotides inhibit intimal arterial smooth muscle cell accumulation in vivo. Nature (Lond.). 359:67-70.

15. Reilly, C. F. 1990. Rat vascular smooth muscle cells immortalized with SV40 large $T$ antigen possess defined smooth muscle cell characteristics including growth inhibition by heparin. J. Cell. Physiol. 142:342-351.

16. Edelman, E. R., M. A. Nugent, L. T. Smith, and M. J. Karnovsky. 1992. Basic fibroblast growth factor enhances the coupling of intimal hyperplasia and proliferation of vasa vasorum in injured rat arteries. J. Clin. Invest. 89:465-473.

17. Edelman, E. R., L. A. Pukac, and M. J. Karnovsky. 1993. Protamine and protamine-insulins exacerbate the vascular response to injury. J. Clin. Invest. 91:2308-2313.

18. Clowes, A. W., M. M. Clowes, J. Fingerle, and M. A. Reidy. 1989. Kinetics of cellular proliferation after arterial injury. V. Role of acute distension in the induction of smooth muscle proliferation. Lab. Invest. 60:360-364.

19. Gewirtz, A. M., G. Anfossi, D. Venturelli, S. Valpreda, R. Sims, and B. Calabretta. 1989. G1/S transition in normal human T-lymphocytes requires the nuclear protein encoded by c-myb. Science (Wash. DC). 245:180-183.

20. Simons, M., K. G. Morgan, C. Parker, E. Collins, and R. D. Rosenberg. 1993. The proto-oncogene $\mathrm{c}$-myb mediates an intracellular calcium rise during the late G1 phase of the cell cycle. J. Biol. Chem. 268:627-632.

21. Travali, S., A. Ferber, K. Reiss, C. Sell, J. Koniecki, B. Calabretta, and R. Baserga. 1991. Effect of the myb gene product on expression of the PCNA gene in fibroblasts. Oncogene. 6:887-894.

22. Bravo, R. 1986. Synthesis of the nuclear protein (PCNA) and its relationship with DNA replication. Exp. Cell Res. 163:287.

23. Miyachi, K., M. J. Fritzler, and E. M. Tan. 1978. Autoantibody to a nuclear antigen in proliferating cells. J. Immunol. 121:2228-2234.

24. Bravo, R., P. A. Frank, P. A. Blundel, and Macdonald-Bravo. 1987. Cyclin/PCNA is the auxiliary protein of DNA polymerase $\delta$. Nature (Lond.). 326:515-517.

25. Prelich, G., and B. Stillman. 1988. Coordinating leading and lagging strand synthesis during SV40 DNA replication in vitro requires PCNA. Cell. 53:117-126.

26. Morishita, R., F. G. Gibbons, K. E. Ellison, M. Nakajima, L. Zhang, Y. Kaneda, T. Ogihara, and V. J. Dzau. 1993. Single intraluminal delivery of antisense cdc2 kinase and proliferating-cell nuclear antigen oligonucleotides results in chronic inhibition of neointimal formation. Proc. Natl. Acad. Sci. USA. 90:84748478.

27. Offermann, M. K., and R. M. Medford. 1993. Induction of VCAM-1 gene expression by double stranded RNA occurs by a P68 kinase-dependent pathway in endothelial cells. Clin. Res. 41:262a. (Abstr.)

28. Woolf, T. M., D. A. Melton, and C. G. Jennings. 1992. Specificity of antisense oligonucleotides in vivo. Proc. Natl. Acad. Sci. USA. 89:7305-7309.

29. Nobuyoshi, M., T. Kimura, H. Ohishi, H. Horiuchi, H. Nosaka, N. Hamasaki, H. Yokoi, and K. Kim. 1991. Restenosis after percutaneous transluminal coronary angioplasty: pathologic observations in 20 patients. J. Am. Coll. Cardiol. 17:433-439.

30. Dilley, R. J., J. K. McGeachie, and F. J. Prendergast. 1988. A review of the histological changes in vein-to-artery grafts, with particular reference to intimal hyperplasia. Arch. Surg. 123:691-696.

31. Schwartz, S. M., and M. A. Reidy. 1987. Common mechanisms of proliferation of smooth muscle in atherosclerosis and hypertension. Hum. Pathol. 18:240-247.

32. Popma, J. J., R. M. Califf, and E. J. Topol. 1991. Clinical trials of restenosis after coronary angioplasty. Circulation. 84:426-436. 